\title{
Dielectrophoretic characterization and separation of micro-organisms
}

\author{
Gerard H. Markx, Ying Huang, Xiao-Feng Zhou and Ronald Pethig
}

Institute of Molecular and Biomolecular Electronics, University of Wales, Dean Street, Bangor, Gwynedd LL57 1UT, UK

\author{
Authors for correspondence: Gerard H. Markx and Ronald Pethig. Tel: +44248 351151. Fax: +44 248361429. \\ e-mail (JANET): gerard@uk.ac.bangor.sees; ron@uk.ac.bangor.sees
}

Keywords: Dielectrophoresis, yeast, bacteria, separation, conductivity

\begin{abstract}
The effective electrical conductivity values for a variety of Gram-negative and -positive bacteria have been determined in the frequency range $10 \mathrm{kHz}$ to $100 \mathrm{kHz}$. This information enabled experimental conditions to be selected where micro-organisms of different species can be separated using dielectrophoresis - the movement of particles induced by non-uniform AC electric fields. Mixtures of micro-organisms of different species were separated locally on a microscope slide using micro-electrodes of polynomial geometry, and their physical isolation into two separate suspensions was accomplished using a dielectrophoresis chamber that incorporated interdigitated, castellated micro-electrodes.
\end{abstract}

\section{INTRODUCTION}

Dielectrophoresis is the movement of particles in nonuniform electric fields (Pohl, 1978; Pethig, 1979, 1991). Unlike electrophoresis, charges on the particle itself are not necessary for the effect to occur and $\mathrm{AC}$ rather than DC fields are employed.

When an electric field is applied to a system consisting of particles (cells) suspended in a liquid medium, a dipole moment is induced in each particle as a result of electrical polarizations forming at the interfaces that define their structure (Pethig, 1991). If the field is non-uniform the particles experience a translational force, known as the dielectrophoretic force, of magnitude and polarity dependent on the electrical properties of the particles and their surrounding medium. This force is also a function of the magnitude and frequency of the applied electric field.

For a spherical particle of radius $\mathrm{R}$ in an imposed electric field $E$ of angular frequency $\omega$, the time-averaged value of the dielectrophoretic force $F(\omega)$ is given by the expression (Pethig, 1991)

$\mathrm{F}(\omega)=2 \pi \varepsilon_{0} \varepsilon_{\mathrm{m}} \mathrm{R}^{3} \operatorname{Re}\left[\frac{\sigma_{\mathrm{p}}^{*}-\sigma_{\mathrm{m}}^{*}}{\sigma_{\mathrm{p}}^{*}+2 \sigma_{\mathrm{m}}^{*}}\right] \nabla \mathrm{E}^{2}$ (r.m.s.)

where Re signifies that the real component of the expression within the square brackets is to be taken, symbol $\nabla$ is the del operator and $\nabla E$ defines the field nonuniformity. In equation (1) $\varepsilon_{0}$ is the permittivity of free space $\left(8.854 \times 10^{-12} \mathrm{~F} \mathrm{~m}^{-1}\right), \varepsilon_{\mathrm{m}}$ is the relative permittivity of the suspending medium, whilst $\sigma_{\mathrm{p}}^{*}$ and $\sigma_{\mathrm{m}}^{*}$ are the complex AC conductivity values of the particle and suspending medium, respectively. In many cases, and in particular for the work described here, the suspending medium is aqueous-based and over the frequency range of interest (typically $10 \mathrm{~Hz}-100 \mathrm{MHz}$ ) exhibits no significant dielectric losses, so that its conductivity and permittivity remain constant. The situation is not so straightforward for the cells, however, and their complex conductivity $\sigma_{\mathrm{p}}^{*}$ can vary significantly with frequency, which in turn dictates the form of their dielectrophoretic frequency spectrum (Wang et al., 1993).

In general, for the frequency range between $10 \mathrm{~Hz}$ and $100 \mathrm{MHz}$, bacteria exhibit four different regimes of dielectrophoretic behaviour. For frequencies typically below $10 \mathrm{kHz}$ the dielectrophoretic force is strongly influenced by an anomalous and as yet not properly understood polarization effect that appears to be associated with charges at the cell surface (Burt et al., 1990; Pethig et al., 1992). With increasing frequency up to around $100 \mathrm{kHz}$, two new regimes of behaviour take over, the first controlled by ionic relaxations and conduction at the cell wall, the next by dipolar and ionic dielectric losses occuring at the cell membrane (Inoue et al., 1988; Burt et al., 1990; Gascoyne et al., 1992; Huang et al., 1992). As the frequency is increased above $1 \mathrm{MHz}$ the capacitive component of the cell membrane acts as a low AC reactance to bypass the high resistance of the membrane, so that the electric field penetrates the cell and internal structures and properties begin to control the dielectrophoretic behaviour (Pethig, 1991). In the frequency ranges where dielectric dispersions occur, the effective conductivity and dielectrophoretic response of 
the cell suspension change significantly with frequency, and elsewhere frequency-independent plateau regions occur (Wang et al., 1993). In this work we are concerned with cell wall and cell membrane properties, and so our determination of $\sigma_{\mathrm{p}}$ has been accomplished by measurement of the dielectrophoretic response at plateau regions occuring in the frequency range between $10 \mathrm{kHz}$ and $100 \mathrm{kHz}$. In this frequency range, to a good approximation, equation (1) can be simplified by the equality

$\operatorname{Re}\left[\frac{\sigma_{\mathrm{p}}^{*}-\sigma_{\mathrm{m}}^{*}}{\sigma_{\mathrm{p}}^{*}+2 \sigma_{\mathrm{m}}^{*}}\right]=\frac{\sigma_{\mathrm{p}}-\sigma_{\mathrm{m}}}{\sigma_{\mathrm{p}}+2 \sigma_{\mathrm{m}}}$

where $\sigma_{\mathrm{p}}$ is the effective conductivity of the cells at the narrow range of frequencies delineating the plateau region.

The background theory and implications of equation (1) and (2) are described elsewhere (Saur, 1985; Pethig et al., 1992; Wang et al., 1993) and it is sufficient for present purposes to ascertain from this equation that if the effective complex conductivity of the particle exceeds that of the suspending medium the resulting dielectrophoretic force is positive. This means that the particle experiences a translational force directed towards regions of high electric field strength. On the other hand, if the particle's conductivity is less than that of the medium, a negative dielectrophoretic force will direct it away from high field regions. The basis of the separation technique described in this paper thus involves selecting a medium conductivity and electric field frequency whereby different particle types in a mixture experience dielectrophoretic forces of opposite polarity.

To be able to determine beforehand whether separation of different cell types is possible it is necessary to know their effective conductivities. This can be achieved simply and relatively quickly using optical techniques developed in our laboratory (Price et al., 1988; Burt et al., 1989). The rate of decrease in the optical absorbance of a suspension, on applying $\mathrm{AC}$ voltages to microelectrodes incorporated into the optical chamber, accurately reflects the dielectrophoretic polarizibility of the particles in the suspension. If $\Delta A$ is defined as the rate of decrease of optical absorbance, and if measurements are restricted to the low frequency plateau region where the dielectrophoretic response is frequency-invariant, then from equations (1) and (2)

$\Delta A=\mathrm{k}\left[\frac{\sigma_{\mathrm{p}}-\sigma_{\mathrm{m}}}{\sigma_{\mathrm{p}}+2 \sigma_{\mathrm{m}}}\right]$

where $\mathrm{k}$ is a constant for a particular experiment. The method for obtaining the effective conductivity $\sigma_{\mathrm{p}}$ of a particular micro-organism consists of determining the value of $\Delta A$ for a range of conductivity values $\sigma_{\mathrm{m}}$ of the suspending fluid.

\section{METHODS}

Micro-organisms. Baker's yeast (Saccharomyces cerevisiae, strain RXII, from the Free University of Berlin) was grown at $30^{\circ} \mathrm{C}$ in a medium containing $5 \%(\mathrm{w} / \mathrm{v})$ sucrose, $0.5 \%$ peptone and $0.5 \%$ yeast extract $(\mathrm{pH} 5.5)$. The yeast was grown overnight, harvested by centrifugation and washed four times in $280 \mathrm{mM}$ mannitol.
Bacillus megaterium NCIMB 9376, Klebsiella rubiacearum (Klebsiella pneumoniae subsp. pneumoniae) NCIMB 9478, Lactobacillus brevis NCIMB 11973 and Pediococcus damnosus NCIMB 12010 were obtained from the NCIMB. Bacillus subtilis 168, Acinetobacter calcoaceticus DSM 586, Enterococcus faecalis DS16 (cured of PAD1), Lactococcus lactis MG1614 and Pseudomonas putida $\mathrm{PaW} 340$ were obtained through Dr M. Young (Department of Biological Sciences, University of Wales, Aberystwyth, UK). Agrobacterium tumefaciens 5A and Erwinia carotovora 16F were from Dr L. Manchester (Department of Biological Sciences, University of Wales, Aberystwyth, UK). B. subtilis, Kl. rubiacearum and Ps. putida were grown overnight at $30^{\circ} \mathrm{C}$ in nutrient broth (Oxoid), whilst Ag. tumefaciens, Erw. carotovora, Ac. calcoaceticus and Ent. faecalis were grown overnight at $30^{\circ} \mathrm{C}$ on nutrient broth with $1 \%(\mathrm{w} / \mathrm{v})$ glucose. $B$. megaterium was grown overnight at $30^{\circ} \mathrm{C}$ in nutrient broth with $1 \%$ glucose and $0 \cdot 1 \% \mathrm{MgCl}_{2} \cdot 6 \mathrm{H}_{2} \mathrm{O}$. Lact. lactis and L. brevis were grown overnight at $30^{\circ} \mathrm{C}$ on MRS broth (Oxoid), whilst Ped. damnosus was grown for $4 \mathrm{~d}$ at $25^{\circ} \mathrm{C}$ on MRS broth with $0.5 \mathrm{~g}$ cysteine $\mathrm{l}^{-1}$. Rhodobacter sphaeroides NM13 was from Drs J. P. Armitage and A. Bell (Biochemistry Department, Oxford University, UK) and grown anaerobically for $4 \mathrm{~d}$ under illumination at $25^{\circ} \mathrm{C}$ on a medium described by Sistrom (1977). Micrococcus lysodeikticus ATCC 4698 and Escherichia coli ATCC 11303 were obtained as lyophilized cells from Sigma. The bacteria (except E. coli and $M$. lysodeikticus) were harvested by centrifugation and washed four times in $280 \mathrm{mM}$ mannitol. The optical absorbance of the cell suspension was adjusted to a value of 0.38 at $655 \mathrm{~nm}$ (for $M$. lysodeikticus and cells of similar size corresponding to about $4.5 \times 10^{7}$ cells $\mathrm{ml}^{-1}$ ) in the dielectrophoresis chamber and the conductivity of the suspensions was changed to the desired value by the addition of small amounts of concentrated $\mathrm{NaCl}$ solution. The conductivities of the suspensions were determined using a Hewlett Packard (model 4192A) impedance analyser operating at a frequency of $10 \mathrm{kHz}$, using platinum-black electrodes of cell constant $1.536 \mathrm{~cm}^{-1}$. The bacterial concentrations were too low to affect the conductivity values.

Dielectrophoretic separation. Four-terminal 'polynomial' electrodes (Huang \& Pethig, 1991) and interdigitated electrodes of castellated design (Price et al., 1988; Inoue et al., 1988; Burt et al., 1990; Pethig et al., 1992) were used. These electrode systems were deposited onto microscope slides using photolithographic fabrication techniques (Price et al., 1988; Burt et al., 1989). The polynomial electrodes, of $40 \mu \mathrm{m}$ separation between opposing electrodes, were primarily used to check for the occurrence of either positive or negative dielectrophoresis. This was achieved by pipetting a small sample of the cell suspension onto the electrodes and applying a $4 \mathrm{~V}$ peak-to-peak sinusoidal signal. Cells that exhibit positive dielectrophoresis collect at the electrode edges, whilst those experiencing negative dielectrophoresis collect in the central region between the electrode tips (Huang \& Pethig, 1991).

For the physical separation of cell mixtures, a small chamber was constructed above an interdigitated electrode array (of characteristic castellated dimension $40 \mu \mathrm{m}$ ) on a microscope slide, using a $200 \mu \mathrm{m}$ plastic (PTFE) spacer and a microscope slide cover-slip. The suspending medium could be flushed in and out of the chamber using two small tubes and a syringe. After introduction of a cell mixture of the appropriate conductivity, an $8 \mathrm{~V}$ peak-to-peak signal of the appropriate frequency was used to separate the cells. With yeast undergoing negative dielectrophoresis, the cells could be seen collecting in triangular aggregations between the electrode castellations (Pethig et al., 1992) and levitated above the electrodes. With many bacteria, because of their small size, such negative dielectrophoretic collection could not be seen as clearly. However, all cell types 


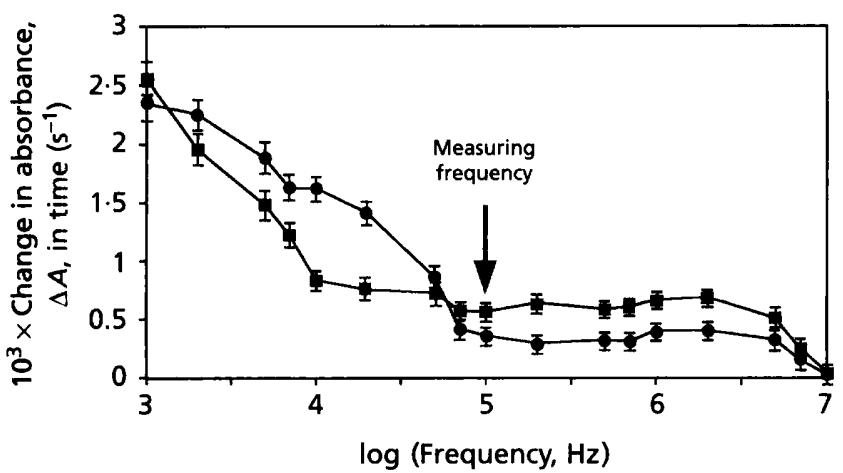

Fig. 1

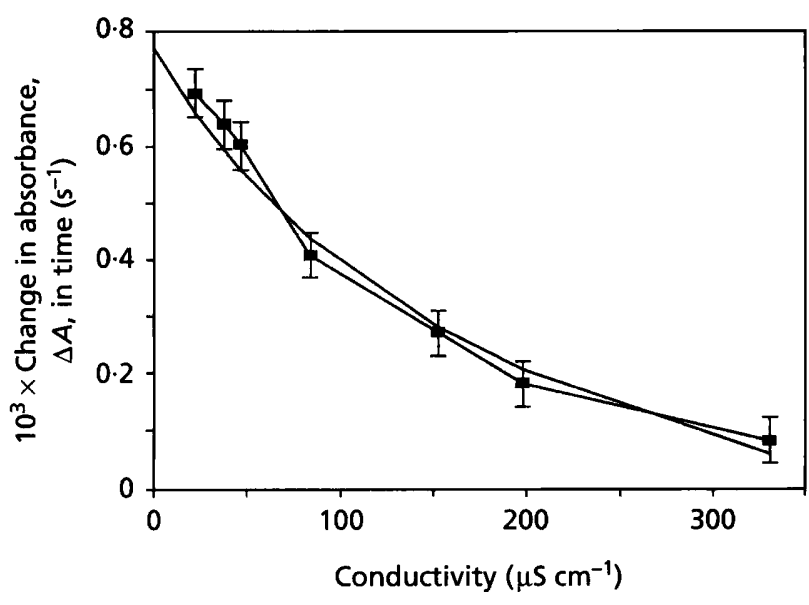

Fig. 2

Fig. 1. Dielectrophoretic spectrum of $E$. coli at two suspension medium conductivities $\left(\mathbb{Q}, 51 \mu \mathrm{cm}^{-1} ; 0,133 \mu \mathrm{cm}^{-1}\right)$. From these spectra the value of $100 \mathrm{kHz}$, corresponding to the low frequency end of the frequency-independent regime, was chosen for the measurement of the effective particle conductivity $\sigma_{\mathrm{p}}$ of $E$. coli.

Fig. 2. Rate of dielectrophoretically induced change, $\Delta A$, in absorbance (eqn. 3 ) of $E$. coli as a function of the conductivity of the suspending medium. Curve fitting of this data gives an effective particle conductivity value of $412 \pm 25 \mu \mathrm{S} \mathrm{cm}^{-1}$.

experiencing positive dielectrophoresis could be observed to collect at the electrode edges. On maintaining the AC voltage to the electrodes and flushing the chamber through with suspending medium, the cells undergoing positive dielectrophoresis were retained whilst those collected in triangular aggregations were carried out of the chamber. Separate collection of the cell types that exhibited positive dielectrophoresis could then be achieved by removing the $\mathrm{AC}$ voltage signal and flushing through with more medium.

Measurement of the effective particle conductivity of bacteria. The effective particle conductivity $\sigma_{\mathrm{p}}$ of bacteria was determined, as outlined in the derivation of equation (3), by measuring the rate of decrease of optical absorbance $(\Delta A)$ as a function of the conductivity $\sigma_{\mathrm{m}}$ of the suspending medium and using a dielectrophoresis chamber with interdigitated electrodes of $40 \mu \mathrm{m}$ castellations. The value of $\mathrm{k}$ in equation (3) was derived by extrapolation of $\sigma_{\mathrm{m}}$ to zero medium conductivity. Rearrangement of equation (3) gives

$\sigma_{\mathrm{m}}=\left[\frac{\mathrm{k}-\Delta A}{2 \Delta A+\mathrm{k}}\right] \sigma_{\mathrm{p}}$

Thus plotting $\sigma_{\mathrm{m}}$ versus the known expression in square brackets of equation (4) gives a straight line with slope $\sigma_{\mathrm{p}}$. Data were fitted with a straight line using the linear regression routines in Quattro-Pro (Borland). Data were also fitted directly to equation (3) using a non-linear fitting routine written in MatLab 4.0 (The Mathworks Inc.) and employing the Nelder-Mead minimization routine (Nelder \& Mead, 1964). The results of these two methods produced values for $\sigma_{\mathrm{p}}$ in close agreement with each other.

To check that a cell exhibits negative (or positive) dielectrophoresis when the medium conductivity is greater (or less) than the effective particle conductivity, cells were suspended in $280 \mathrm{mM}$ mannitol and the conductivity was progressively increased by addition of small amounts of $1 \mathrm{M} \mathrm{NaCl}$. Samples of these suspensions were then pipetted onto the polynomial electrode system for investigation of their dielectrophoretic properties.

\section{RESULTS}

\section{Measurement of the effective conductivity}

Dielectrophoretic spectra and the effective particle conductivities of a range of micro-organisms were determined; as a specific example the procedure for $E$. coli will be described. The dielectrophoretic spectrum of $E$. coli over the frequency range $1 \mathrm{kHz}$ to $10 \mathrm{MHz}$ for two different suspension conductivities is shown in Fig. 1. From these spectra it was concluded that the particle conductivity should be determined at $100 \mathrm{kHz}$, where the dielectrophoretic behaviour was relatively frequencyindependent. The rate of change $\Delta A$ in the absorbance of an $E$. coli suspension at different conductivities $\sigma_{\mathrm{m}}$ was measured and the results, complete with the non-linear fitting to the data according to equation (3), are shown in Fig. 2. This analysis, together with the graphical procedure utilizing equation (4), provided a value of $412 \pm 25 \mu \mathrm{S} \mathrm{cm}^{-1}$ for the effective particle conductivity of $E$. coli at $100 \mathrm{kHz}$. This result, together with those obtained for the other micro-organisms, is given in Table 1.

\section{Separation of micro-organisms}

Inspection of Table 1 reveals that the effective conductivities of the various micro-organisms cover a broad range, and that their separation by dielectrophoresis (e.g. of $B$. 
Table 1. Effective particle conductivity $\sigma_{\mathrm{p}}$ of a number of micro-organisms as estimated by dielectrophoresis and equation (3)

The optimum frequency of measurement was chosen, as described in the text, on the basis of the dielectrophoretic spectra for each micro-organism.

\begin{tabular}{|lccc|}
\hline Species & $\begin{array}{c}\text { Gram } \\
\text { stain }\end{array}$ & $\begin{array}{c}\text { Frequency } \\
(\mathbf{k H z})\end{array}$ & $\begin{array}{c}\boldsymbol{\sigma}_{\mathbf{p}} \\
\left(\boldsymbol{\mu S} \mathbf{c m}^{-1}\right)\end{array}$ \\
\hline Acinetobacter calcoaceticus & - & 25 & $<20$ \\
Agrobacterium tumefaciens & - & 100 & $452 \pm 50$ \\
Bacillus megaterium & + & 10 & $888 \pm 39$ \\
Bacillus subtilis & + & 10 & $935 \pm 96$ \\
Enterococcus faecalis & + & 10 & $230 \pm 21$ \\
Erwinia carotovora & - & 10 & $20 \pm 9$ \\
Escherichia coli & - & 100 & $412 \pm 25$ \\
Klebsiella rubiacearum & - & 10 & $513 \pm 102$ \\
Lactobacillus brevis & + & 25 & $153 \pm 18$ \\
Lactococcus lactis & + & 25 & $416 \pm 46$ \\
Micrococcus lysodeikticus & + & 15 & $1557 \pm 116$ \\
Pediococcus damnosus & + & 10 & $1018 \pm 68$ \\
Pseudomonas putida & - & 10 & $195 \pm 14$ \\
Rbodobacter sphaeroides & - & 15 & $967 \pm 53$ \\
Saccharomyces cerevisiae & & 10 & $16 *$ \\
\hline
\end{tabular}

* Data from Huang et al. (1992).

subtilis from E. coli, or yeast cells from most of the bacteria except Erw. carotovora and Ac. calcoaceticus) should be possible, and has indeed been demonstrated in this laboratory. The essential requirements are a suspending medium of conductivity value between the effective conductivities of the two species of micro-organism, and an applied voltage frequency intermediate between those used to determine the effective particle conductivity.

Polynomial electrodes were used to check that the cells exhibited negative dielectrophoresis when suspended in medium conductivities larger than their measured effective particle conductivity $\sigma_{\mathrm{p}}$. In agreement with the finding of Price et al. (1988) it was found that the dielectrophoretic force did not exhibit a sharp transition from a positive to a negative value on increasing the suspending medium conductivity $\sigma_{\mathrm{m}}$ above that of $\sigma_{\mathrm{p}}$. Negative dielectrophoresis could only be seen for $\sigma_{\mathrm{m}}$ values considerably higher than $\sigma_{\mathrm{p}}$. None of the cells exhibited positive dielectrophoresis when $\sigma_{\mathrm{m}}$ exceeded $\sigma_{\mathrm{p}}$.

An example of localized separation of two types of bacteria using the polynomial electrodes is shown in Fig. 3 , for the case of a mixture of E. coli and M. lysodeikticus suspended in $280 \mathrm{mM}$ mannitol adjusted to a conductivity of $550 \mu \mathrm{S} \mathrm{cm}^{-1}$ using $1 \mathrm{M} \mathrm{NaCl}$. A signal of $4 \mathrm{~V}$ peak-topeak at $100 \mathrm{kHz}$ was applied to the electrodes, and as shown in Fig. 3 dielectrophoretic separation of the two species occurred with $E$. coli being directed to the central region between the electrodes and $M$. lysodeikticus collecting at the electrode edges. This separation effect could

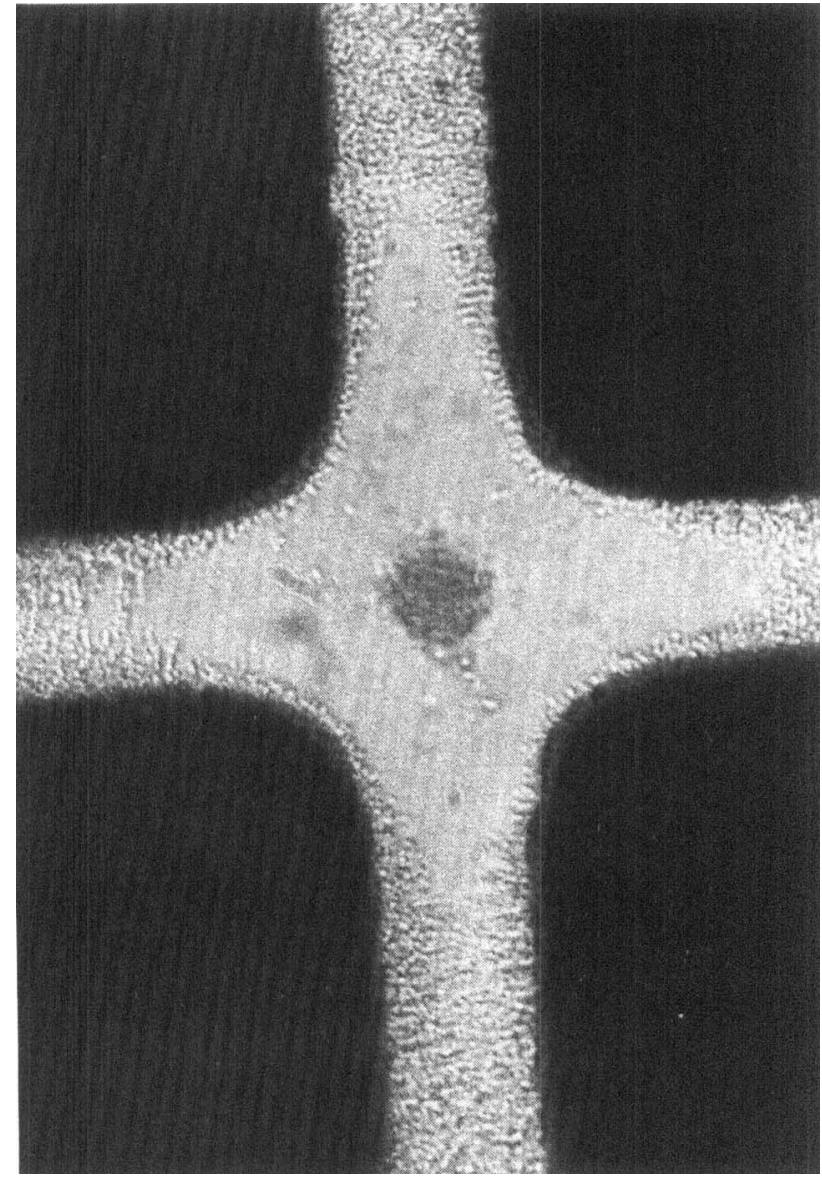

Fig. 3. Dielectrophoretic separation of $E$. coli (experiencing negative dielectrophoresis) and $M$. lysodeikticus (experiencing positive dielectrophoresis) in a polynomial electrode system after application of a $4 \mathrm{~V}$ peak-to-peak sinusoidal $100 \mathrm{kHz}$ signal. The suspending medium was $280 \mathrm{mM}$ mannitol of conductivity of $550 \mu \mathrm{sm}^{-1}$. Bar, $25 \mu \mathrm{m}$.

be repeated with mixtures of many of the other bacterial species listed in Table 1.

Although localized separation of cell types can be achieved using the polynomial electrodes, their physical isolation into two separate suspensions is not possible using this method. This can be accomplished, however, using the interdigitated and castellated electrodes. For example, a mixture of yeast cells and $M$. lysodeikticus in $280 \mathrm{mM}$ mannitol $/ 1 \mathrm{mM} \mathrm{NaCl}$ was introduced into the dielectrophoretic separation chamber (see Fig. 4a). As shown in Fig. 4(b) the bacterial cells collected at the edges of the electrodes within a few seconds of the application of an $8 \mathrm{~V}$ peak-to-peak $10 \mathrm{kHz}$ signal, whilst the yeast cells were either repelled from the electrodes into triangularshaped aggregations or were levitated above the electrode plane. With the voltage signal still applied, flushing the electrode chamber through with the suspending medium resulted in the selective removal and collection of the yeast cells (Fig. 4c). The M. lysodeikticus cells were then 


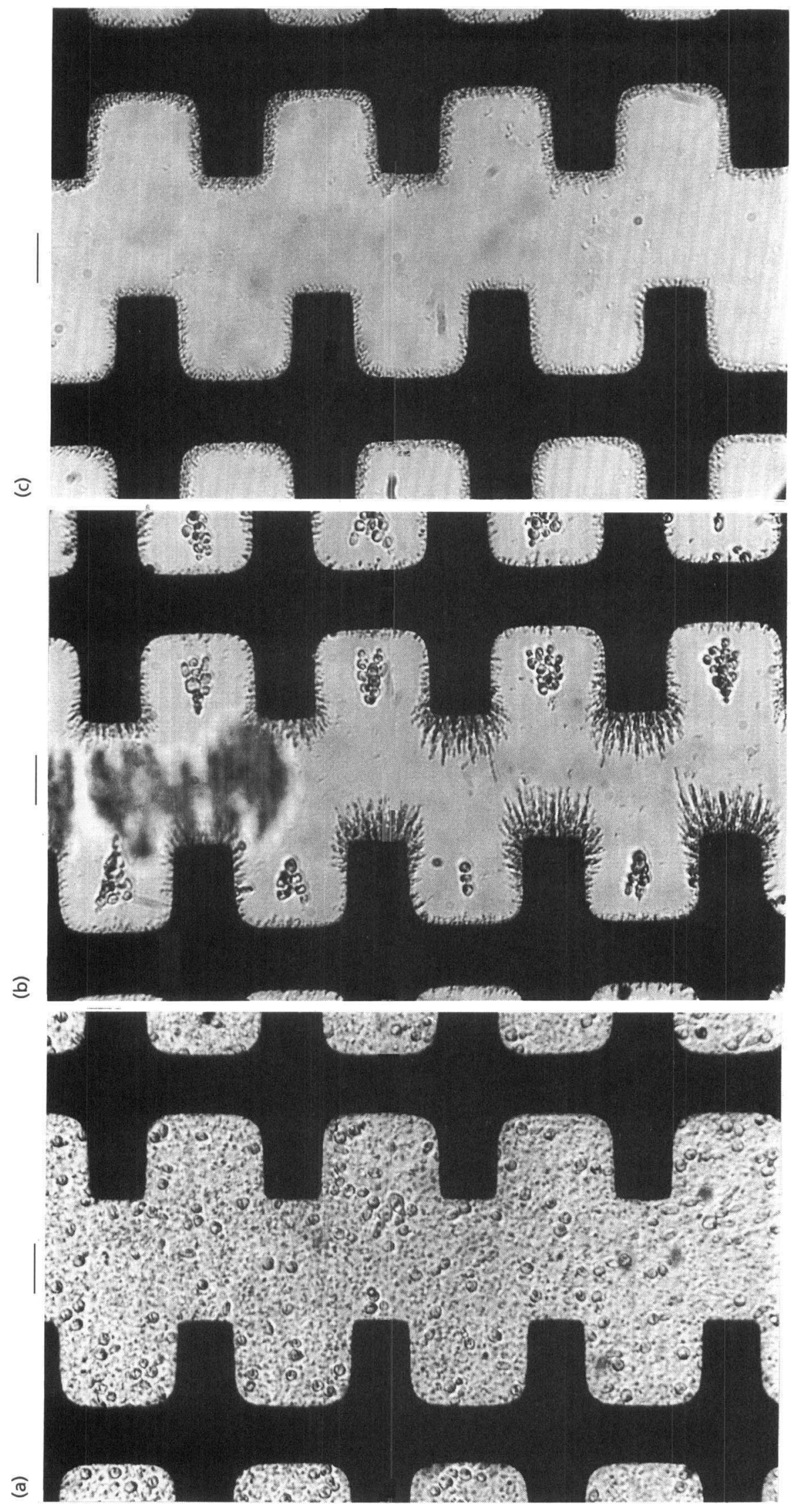

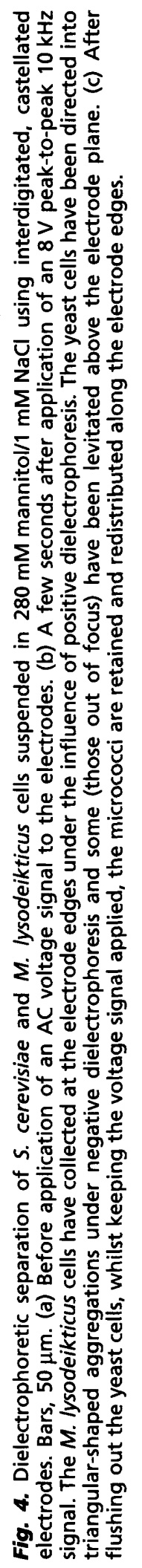


collected by first removing the voltage signal and flushing them out of the chamber. This procedure could be repeated for mixtures of various bacteria, e.g. mixtures of M. lysodeikticus and E. coli, and B. subtilis and E. coli.

\section{DISCUSSION}

Relatively few investigations have been reported of the AC electrical properties of micro-organisms. Yeast has been studied using a variety of techniques (Harris $e t$ al., 1987; Hölzel \& Lamprecht, 1992; Huang et al., 1992; Wang et al., 1993), but most information concerning bacteria derives from the pioneering dielectric studies of E. L. Carstensen and co-workers (Carstensen et al., 1965; Carstensen, 1967; Carstensen \& Marquis, 1968, 1975; Einolf \& Carstensen, 1967, 1969; Marquis \& Carstensen, 1973). At low frequencies the electrical properties of bacteria were concluded (Carstensen \& Marquis, 1968; Einolf \& Carstensen, 1969) to be dominated by the relatively high conductivity of the cell wall, with the cell interior being screened from low frequency imposed electric fields by the insulating inner plasma membrane (Pethig, 1979). These results were confirmed by dielectrophoretic measurements on $M$. lysodeikticus (Inoue et al., 1988). Carstensen and co-workers (Carstensen et al., 1965; Carstensen \& Marquis, 1968) also found that the electrical properties of the cell wall changed significantly with culturing conditions and culture age, which is an aspect we have not addressed here. However, the finding (Einolf \& Carstensen, 1967; Marquis \& Carstensen, 1973; Carstensen \& Marquis, 1975) that the electrical properties of bacteria can vary markedly between species is in accordance with the results given in Table 1 .

Bacteria are often classified according to the results of the Gram-staining procedure. Gram-positive bacteria synthesize a uniform peptidoglycan-structured cell wall, whilst Gram-negative cells have a more complicated cell wall structure which includes lipids and proteins forming an outer membrane covering a layer of peptidoglycan. The cell walls of Gram-positive bacteria are also characterized by the incorporation of teichoic acids forming open networks with high charge densities comparable with ion-exchange materials (Ou \& Marquis, 1970). The presence of such charged groups and the absence of an outer lipid membrane may account for the conductivity of Gram-positive bacteria tending to be higher (Table 1) than that of the Gram-negatives, although exceptions occur (e.g. the high conductivity of Rhod. sphaeroides and the relatively low conductivities of Ent. faecalis and $L$. brevis), for which we can offer no explanation. The low effective conductivity of yeast reflects the fact that their cell walls consist mainly of (uncharged) polysaccharides (Fleet, 1991).

As described here, dielectrophoresis measurements can be achieved using simple equipment and techniques. Using such techniques we have demonstrated that differences in the effective particle conductivities of bacteria are expressed as differences in their dielectrophoretic properties, which in turn can be exploited as a vehicle for the separation of mixtures of bacteria of different species.
Since in principle a single bacterium can be investigated, this facility could be of assistance in the early identification of bacteria (of importance for example in clinical microbiology). Also, the separation of yeast cells from bacteria could find use, for example, in quality monitoring and control of fermentation and food production processes.

\section{ACKNOWLEDGEMENTS}

This work has been supported by British Technology Group Ltd. We thank Mr J. Tame for his work on electrode photolithography, R. Hölzel for the yeast strain, M. Young, L. Manchester, J. P. Armitage and A. Bell for bacteria and J. P. H. Burt, P. R. C. Gascoyne, M. S. Talary, M. Young and X. B. Wang for valuable discussions.

\section{REFERENCES}

Burt, J. P. H., Al-Ameen, T. A. K. \& Pethig, R. (1989). An optical dielectrophoresis spectrometer for low-frequency measurements on colloidal suspensions. J Pbys E Sci Instrum 22, 952-957.

Burt, J. P. H., Pethig, R., Gascoyne, P. R. C. \& Becker, F. F. (1990). Dielectrophoretic characterisation of Friend murine erythroleukaemic cells as a measure of induced differentiation. Biochim Biopbys Acta 1034, 93-101.

Carstensen, E. L. (1967). Passive electrical properties of microorganisms. II. Resistance of the bacterial membrane. Biophys $J 7$, 493-503.

Carstensen, E. L. \& Marquis, R. E. (1968). Passive electrical properties of microorganisms. III. Conductivity of isolated bacterial cell walls. Biophys $J$ 8, 536-548.

Carstensen, E. L. \& Marquis, R. E. (1975). Dielectric and electrochemical properties of bacterial cells. In Spores VI, Proceedings of the 6th International Spore Conference Michigan, pp. 563-571. Edited by P. Gerhardt, R. N. Costilow \& H. L. Sadoff. Washington, DC: American Society for Microbiology.

Carstensen, E. L., Cox, H. A., Mercer, W. B. \& Natale, L. A. (1965). Passive electrical properties of microorganisms. I. Conductivity of Escherichia coli and Micrococcus lysodeikticus. Biopbys J 5, 289-300.

Einolf, C. W. \& Carstensen, E. L. (1967). Bacterial conductivity in the determination of surface charge by microelectrophoresis. Biocbim Biopbys Acta 148, 506-516.

Einolf, C. W. \& Carstensen, E. L. (1969). Passive electrical properties of microorganisms. IV. Studies of the protoplasts of Micrococcus lysodeikticus. Biophys J 9, 634-643.

Fleet, G. H. (1991). Cell walls. In The Yeasts, vol. 4, 2nd edn, pp. 199-277. Edited by A. H. Rose \& J. S. Harrison. London: Academic Press.

Gascoyne, P. R. C., Huang, Y., Pethig, R., Vykoukal, J. \& Becker, F. F. (1992). Dielectrophoretic separation of mammalian cells studied by computerized image analysis. Meas Sci Techno/3, 439-445.

Harris, C. M., Todd, R. W., Bungard, S. J., Lovitt, R. W., Morris, J. G. \& Kell, D. B. (1987). Dielectric permittivity of microbial suspensions at radio-frequencies: a novel method for the real-time estimation of microbial biomass. Envyme Microb Technol 9, 181-186.

Hoblzel, R. \& Lamprecht, I. (1992). Dielectric properties of yeast cells as determined by electrorotation. Biochim Biopbys Acta 1104, 195-200.

Huang, Y. \& Pethig, R. (1991). Electrode design for negative dielectrophoresis. Meas Sci Technol 2, 1142-1146.

Huang, Y., Hoblzel, R., Pethig, R. \& Wang, X. B. (1992). Differences in the AC electrodynamics of viable and non-viable yeast cells 
determined through combined dielectrophoresis and electrorotation. Phys Med Biol 37, 1499-1517.

Inoue, T., Pethig, R., Al-Ameen, T. A. K., Burt, J. P. H. \& Price, J. A. R. (1988). Dielectrophoretic behaviour of Micrococcus lysodeikticus and its protoplast. J Electrostat 21, 215-223.

Marquis, R. E. \& Carstensen, E. L. (1973). Electric conductivity and internal osmolality of intact bacterial cells. J Bacteriol 113, 1198 1206.

Nelder, J. A. \& Mead, R. (1964). A simplex method for function minimization. Comput J 7, 308-313.

Ou, L. T. \& Marquis, R. E. (1970). Electromechanical interactions in cell walls of Gram-positive cocci. J Bacteriol 101, 92-101.

Pethig, R. (1979). Dielectric and Electronic Properties of Biological Materials. Chichester: J. Wiley \& Sons.

Pethig, R. (1991). Application of AC electrical fields to the manipulation and characterisation of cells. In Automation in Biotechnology, pp. 159-185. Edited by I. Karube. Amsterdam: Elsevier.

Pethig, R., Huang, Y., Wang, X. B. \& Burt, J. P. H. (1992). Positive and negative dielectrophoretic collection of colloidal particles using interdigitated castellated microelectrodes. J Phys D Appl Pbys 24, 881-888.

Pohl, H. A. (1978). Dielectrophoresis. Cambridge: Cambridge University Press.

Price, J. A. R., Burt, J. P. H. \& Pethig, R. (1988). Applications of a new optical technique for measuring the dielectrophoretic behaviour of micro-organisms. Biochim Biophys Acta 964, 221-230.

Saur, F. A. (1985). Interaction-forces between microscopic particles in an external electromagnetic field. In Interactions between Electromagnetic Fields and Cells, pp. 181-202. Edited by A. Chiabrera, C. Nicolini \& H. P. Schwan. New York: Plenum Press.

Sistrom, W. R. (1977). Transfer of chromosomal genes mediated by plasmid R68.45 in Rbodopseudomonas sphaeroides. J Bacteriol 131, 526-532.

Wang, X. B., Huang, Y., Hölzel, R., Burt, J. P. H. \& Pethig, R. (1993). Theoretical and experimental investigations of the interdependence of the dielectric, dielectrophoretic and electrorotational behaviour of colloidal particles. J Pbys D Appl Pbys 26, 312-322.

Received 29 June 1993; revised 28 July 1993; accepted 23 August 1993. 